\title{
Specific Barriers for Quadruple Helix Innovation Model Development - Case of Croatia
}

Jan Klasinc

University of Zagreb, Croatia

\begin{abstract}
There has been a lot of theoretical discussion about triple helix and quadruple helix methodologies for innovation and knowledge transfer in the context of local development and even smart cities. The goal of this paper is to describe specific barriers related to ICT uptake, usage and development related to knowledge based capital and their role in Croatia, especially in the context of passing from triple helix (academia, business, government) to quadruple helix (academia, business, government, NGOs/citizens) model. Specific barriers exist in each country, and they may be divided into technological, organisational, human, societal and/or cultural barriers. The case of Croatia is specifically analysed and compared to other countries in the region and in the EU. The lack of participative culture and other criteria influencing social dynamics are particularly addressed in order to reach a conclusion about country specific barriers and provide policy advice for decision makers.
\end{abstract}

Keywords: innovation, social entrepreneurship, quadruple helix, knowledge based capital, country specific barriers

JEL classification: $\mathrm{O35}, \mathrm{O} 31$

Acknowledgments: IDEMO, Institute for Democracy

\section{Introduction}

In the past, economics was mostly concerned with events going on micro level, or aggregate data, looking for different types of equilibrium, and simplified models that idealised and generalised a lot in order to reach an "elegant" solution, that sometimes did not accurately predict reality. Recently, the development of economics has taken a new turn, towards behavioural economics, theory of complexity and evolutionary economics, trying to use sometimes more number crunching or take into account less than ideal nature of markets and agents, that are not considered to be completely rational, but instead possessing only bounded rationality and acting in complex adaptive systems that can be compared to living organisms in nature. This kind of approach seems more suitable when looking into social dynamics development concerning economy, or evolution of such systems in time, which is based on lack of equilibrium, rather than some kind of equilibrium, and a typical example might be the analysis of triple and quadruple helix innovation models and their development in the course of time, starting at the beginning of $20^{\text {th }}$ century and leading up to modern era of digitalisation of markets and public administration, pervasive ICT technology and knowledge based economy. The key benefit of triple helix model lies in innovation, or creation, transfer, or modification and utilization of the know-how, stemming from the implementation of scientific and 
research activities carried out by universities in cooperation with enterprises, as well as in increasing human capital and intellectual capital. In this context, it could also be seen as an important stimulus for development and creation of social dynamics that promotes innovation and economic growth in an environment that could be polluted by corruption, bad administration and otherwise bad business practices, such as inadequate taxation. When trying to explain innovation policies, looking into social dynamics may be useful, and the goal of the paper is to point into that direction on the basis of data, suggesting further studies of social dynamics connected to innovation and analysing barriers that prevent innovation, in the particular the case of quadruple helix and the role of social networks. The paper is organised in six parts. After introduction and explaining the methodology, in the third part we explain the methods of measuring knowledge-based capital in a knowledge-based economy. In the next part we explain the triple and quadruple helix models, and in the fifth part we explain particular barriers for development of such models in Croatia on the basis of data. Finally, there is a conclusion.

\section{Methodology}

This paper looks into existing data on Croatian performance concerning several dimensions influencing social dynamics and innovation, such as corruption perception index (CPI), innovation and networking index, devolution of power to regional/local governments, technological and scientific parks, incubators, innovative centres and clusters and other forms of cooperation of government, local government academia and business in innovation on firm level, in order to draw conclusions about country specific barriers to innovation policy based on triple helix and/or quadruple helix model dynamics. One currently possible methodology is to compare Croatia to similar countries in the region, or other countries with successful innovation policies based on triple helix model, using them as benchmarks, taking into account specific development of Croatia and its particular problems, and using the same kind of logic that appeared to be at work in successful countries. To begin with, we mention the case of MIT and Israel as a historical example of emergence of triple helix dynamics, but with a limitation that this development could not be simply copied or reproduced in Croatia, and that technological development in the modern age also calls for different approaches to innovation and enables different or even better ways of development. Czech Republic represents a case of a country with a similar development that tries to escape the middle income trap by innovation policy, trying to compete with advanced economies and not being able to compete with low wage economies (Kascheeva et al., 2015, Blazek et al., 2007). We analyse the importance of knowledge based economy and capital in Croatia, and make conclusions about the possibilities for its expansion, leading to more innovation, paying attention to the problem of corruption. Then we analyse triple and quadruple helix models, and finally we come to the subject of special barriers to their development in Croatia on the basis of above mentioned indexes and other available information. Finally, we propose a classification of the barriers preventing development into technological, organisational, human, social, and cultural, and we analyse in particular significant problems in Croatia: organisational (networking), human (tertiary education), social (predominant social trends, corruption vs. innovation, trust) and cultural (participatory and authoritarian culture including religious dogmatism and possibly other cultural and traditional factors). 


\section{Knowledge Based Economy and Measuring Knowledge Based Capital (KBC)}

Knowledge based capital is defined as non-physical or intangible assets, such as data, software, patents, designs, new organisational processes and firm-specific skills. In addition to this, there is human capital which is regarded as an investment, and not as a cost in a knowledge-based economy. Innovation is a key to business success, and investment in R\&D is not the only way to drive innovation. Business investment in $\mathrm{KBC}$ can boost growth and productivity, and business investment in KBC contributes $20 \%$ to 345 of average labour productivity growth. It also makes firms competitive, and countries that invest more in KBC are also more effective in reallocating resources to innovative firms. United States and Sweden invest about twice as much in KBC s Italy and Spain, and patenting firms in the US and Sweden attracts four times as much capital as similar firms in Italy and Spain. However, insufficient data and problems with measurement further complicate policy making. All this calls for an enlarged concept of innovation, beyond the conventional view in which R\&D is pre-eminent. Other forms of KBC should also be policy targets, and policy should make it easier for firms to develop and commercialise new ideas by lowering the costs of failure and encouraging firms to experiment with potential growth opportunities, while IPR systems should be coupled with pro-competition policies and efficient judicial systems. In their seminal work, Corrado, Hulten and Sichel (Corrado et al., 2005, 2009) made a number of ground-breaking contributions that have led to a better understanding of KBC. They proposed to classify expenditures on KBC into three broad categories: computerised information, innovative property and economic competencies, which is called CHS framework. (OECD, 2013) They also developed an expenditure-based approach to measuring these assets. International datasets such as INTAN-Invest, covering 27 countries of the EU plus Norway and US have appeared out of those efforts. (OECD :: 2013) Another issue is measuring investment in $\mathrm{KBC}$ at the sector and firm levels, where our VAIC index proposed by Mr. Pulić was among the first to recognise such a need. Understanding the patterns of industries' and firms' investments in knowledge-based assets could help in the design of more effective industrial policies, and identification of policy tools. The need for new type of measurement when it comes to triple helix model has been already stressed by Singer and Oberman Peterka at the University of Osijek (Singer, Oberman-Peterka, 2015), and the new kind of indicators that would be more suitable for such measurements.

\section{Quadruple Helix Model and Triple Helix Model}

Triple Helix Model has appeared as a model suitable for explanation of one type of social dynamics in knowledge based society. Its historic roots can be found in the MIT and foundation of the state of Israel, starting in 1920s. MIT was founded in the mid $19^{\text {th }}$ century, in order to address economic decline of New England region, and its extensive network of academic institutions was used as a basis for leadership, which led to transforming usual public-private partnership model into a proto-triple helix configuration. Greater flexibility of this model - a triad - in comparison to usual dyad models that either have a strong command direction or devolve into opposition and stasis (Simmel, 1950), can lead to a synergy and dynamic development due to lack of equilibrium, in comparison to zero-sum game played by industry-government groups (Dubina, 2015). At that time this model was highly unusual in its creativity. The case of Jewish agricultural settlements in a province of Ottoman empire in the early $20^{\text {th }}$ century started by a formation of an agricultural 
institute before the creation of the state of Israel, which was an example of creation of a double helix academia-industry before including the government (Florence, 2007).

Figure 1

Triple Helix Model of Innovation

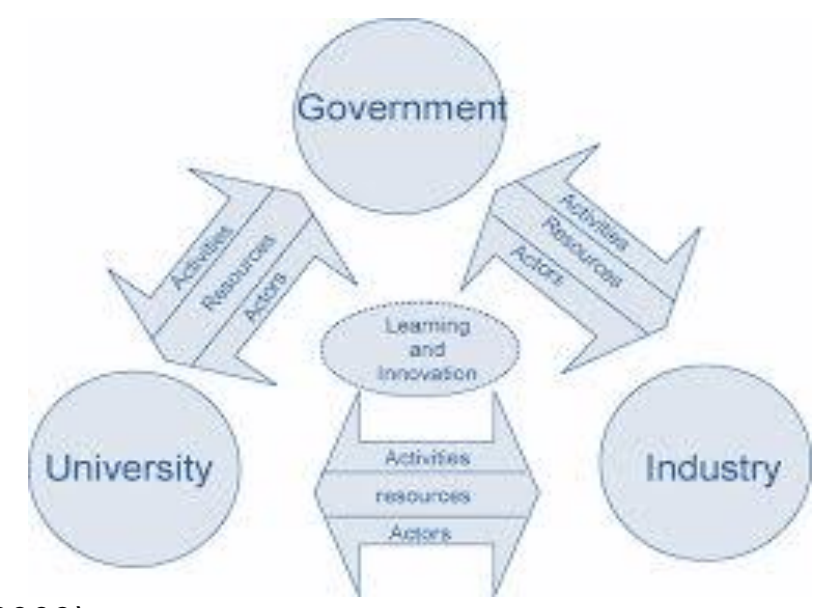

Source: Ełzkowitz (2008)

According to Etzkowitz (2008), there are three levels of the triple helix model. The first level of the triple helix model refers to cooperation within individual vertices of the model, i.e. mutual cooperation between enterprises, cooperation between universities, and cooperation between individual government levels. At the same time, partnerships between enterprises can have different close forms of cooperation. Partnerships between universities can take place both on the educational level and in the scientific and research area. Etzkowitz (2002) differentiates several triple helix models - statist model, laissez-faire model, interaction model and circulation model. Individual models differ in the character of relationships. The most perfect is the circulation model (see Figure 1), which expresses not only the possible knowledge transfer within individual helices of the model and relationships between individual helices, but also the highest form relationships among the entities of all the helices. As this new social dynamics model is based also on networking, breaking of barriers in social institutions and integration/cooperation of different social sectors, it is also true that it must have also been a product of a new type of culture and change of norms in a society, which has occurred mainly after the WWII, in the United States and other western countries, spreading further to the rest of the world, e.g. South Korea, as a typical example. The changes that happened in the 1950s and afterwards, in 1960s and 1970s in the US society were in one part the consequence of baby boom after the end of the war, that increased considerably the younger generation and on the other hand the creation of new culture that emphasised informality and breaking of old structures of authority. This might have led to an increase of the rate of crime (in particular murder) and violence, or the destruction of family life and civilising factors, while otherwise leading to more creativity, towards 'creative destruction' as a model for innovation and development, which could have also been partly influenced by 'eastern' cultures. Another important contribution to the development of the model were the advances in biology research and the discovery of the DNA structure, actual triple and - more recently - quadruple helix structures. 


\section{Specific Barriers for Application of Quadruple Helix Model in Croatia}

There are currently10 scientific centres of excellence in Croatia, numerous technological parks, incubators and hubs that have been created in the recent years, mostly with support of the government and local governments, but also with the help of EU funds and business sector. However, rather poor integration of science in social networks and media and week popularisation of science even in schools seems as one of important barriers for the application of quadruple helix model in Croatia. Nowadays, an important aspect of development of this new kind of social dynamics based on triple and quadruple helix models is the interaction between media and social networks, which is already present in Croatia. However, academic topics can be mostly noted in specialised media, such as poslovna.hr, Lider, and other media dealing with science and technology. Further development can lead to better networking between academia and business, which is the first step towards creation of triple helix social dynamics. For example, the increase of number of users of Linkedln increased employment, due to networking effects, but the index of networking in Croatia, shows rather poor performance, and in order to achieve triple helix social dynamic, the impulse should come either from academia or business, as only they are able to have reactions that are fast enough to meet the demands of an market based on innovation, such as in knowledge based economy, so the role of government should be reduced accordingly.

Looking for correlation between innovation and corruption, it can be shown that higher corruption is usually linked to less innovation, and this could be precisely because more corruption is connected to the more important role of government in business. Or perhaps in academia as well (in which case we are talking about particular type of corruption concerning academic performance, promotion, and graduation of students). In Croatia, CPI has been persistently high, and its association with government is rather high, although not so high in academia, which is still trusted. Businesses are considered to be in the middle between government and academia. Therefore, it would be desirable that the academia, due to its greater independence from state, which is also guaranteed by the constitution and laws, leads in triple helix dynamics. This dynamics could not at first be achieved as innovation itself, although this type of cooperation between business and academia is also desirable, but preferably through cooperation of academia and business concerning training of highly qualified professionals and employment, which could then lead to innovation. Regression on a panel of 26 countries between CPI and Global Innovation Index 2015 shows significant negative correlation between corruption and innovation with a coefficient $r=0,8428$, and quite similar results may be obtained for a regression between CPI and Capacity for Innovation Index (WE Forum), $r=0,8442$.

It appears that USA; South Korea, Israel and Czech Republic show better results in innovation with respect to corruption, which could be accounted by better innovation policies in those countries, perhaps also triple and quadruple helix models, or proposed higher level n-tuple helix models. Partnerships between individual government levels are also affected by distribution of the political power in the given country and by the applied model of fiscal federalism. In particular, in Czech Republic common problems included insufficient focusing on 3E and ideas instead of technicalities, a complicated agenda and rules, lack of strategy and commercialisation (Tetrevova, Kostalova, 2015) In order to promote investment, the 
government should, perhaps, engage more with citizens in the creation of participative culture.

In the most recent 2015 report of the World Economic Forum, Croatia is ranked 54 in Network Readiness Index, with Singapore and Finland at the top, but only 88 in eparticipation, sharing the place with Nigeria and several other countries, with Netherlands, South Korea and Uruguay on the top three places and United Kingdom, France and Japan sharing the fourth place. Also Croatia is only on the 83rd place regarding the time required to start a business, and also has other problems with its business environment, such as with taxation of income and profit, etc. Croatia is ranked only at the $97^{\text {th }}$ place regarding the quality of education system with Switzerland and Finland at the top, but at place 26 regarding quality of mathematics and science education, with Singapore and Finland at the top. Finally, our culture, which is based on traditional Christianity, namely authoritative hierarchy and dogma, may act as barrier to more creativity or creative destruction. For comparison, we can take Poland, Portugal, Slovak Republic and Greece - Poland, despite its well-developed territorial organisation, system of decentralised disbursement of EU funds, and successful economy, has experienced a slowdown in economic growth to 1\%, mainly because it lags in innovation policy. Growth in Poland over the last decade has relied more on technology absorption, than on R\&D and innovation, and global financial crisis has exposed this weakness, demanding new models of growths. Portugal and Greece have had a history of dictatorships, just as Spain, and the Slovak Republic has had an authoritarian regime in the 1990. Czech Republic innovation policy studies show many similarities with Croatia in EU fund management and problems with politicisation of the administration, although it seems that Croatia lags behind due to inadequate decentralisation and devolution of power to local governments, and corruption in the disbursement of EU funds.

One way to explain this negative influence of authoritarian culture is through social dynamics of innovation. We have already argued that hierarchies may be detrimental to innovation, as supervisors will usually reject new or creative ideas as they don't have any personal gain from them; on the other hand, hierarchies support corruption, as the supervisors will have something to gain from the supervised and the supervised will gain a positive evaluation of their work without adding actual value. Thus value will be lost, and in the long run such a company or society will become uncompetitive due to lack of innovation. If we look into individual dynamics, we can imagine individuals $A, B$ and $C$. If $A$ dominates $B$, and $B$ dominates $C$, than $A$ also dominates $C$ (transitivity), and this type of individual linear hierarchy can be further developed into social dynamics that enhances the creation of lines of hierarchy (Chase, Tovey, Spangler-Martin, Manfredonia, 2001), although in the group assembly experiments, in which group interaction proved effective in producing linear hierarchies, the individuals still varied in prior attributes. Ordinarily, the absence of higher-level cognitive ability, behavioural complexity, language skills, and elaborate cultural forms argue against applying lessons learned from studying social organization in simple creatures to the investigation of social systems in humans. However, finding that social interaction is so important in producing organized structures in fish strengthens the argument for investigating the importance of social dynamics in producing dominance hierarchies and other social structures in humans. In other words, existing authoritarian social dynamics in human societies may help create individual lines of hierarchy, which in turn help maintain authoritarian social dynamics, ending in a vicious cycle. However, in real life situations, many other combinations of hierarchies are possible (which applies both 
to animals and humans), which may not be transitive, e.g. such as that $C$ dominates A. In nature many examples of linear hierarchies may be found, although particular social dynamics that creates such hierarchies may be complex and difficult to analyse. In the case of triple helix model for innovation, we could simplify things and imagine that individual $A, B$, and $C$ translate evenly into groups: $A=$ academia, $B=$ business and $C=$ Government. If corruption prevails, the agents will orient themselves towards the most powerful sector of society, such as government, or political parties and lines of hierarchy will be formed towards that sector, thus acting as a barrier for innovation. This may explain insufficient success of Croatian scientific centres of excellence, technological parks, SME incubators and other predominantly government funded actions to increase innovation and attract investment. On the basis of the case of Czech Republic, which has been a leader in the CEE region in innovation, although not as good in combating corruption, just as Croatia, it could be argued that the introduction of triple helix model and spillovers from other EU countries, such as Germany, were able to create centres of excellence that reversed the corruption trend, and that such foci of change were made also by triple helix methodology for innovation, thus enabling the Czech Republic to score better; another important decision was to decentralise the country and the devolution of power to regions enabled better application of triple helix policy than in a country that is as centralised as Croatia, although it did not automatically translate into reduction of corruption. The stark opposition between corruption logic and innovation logic should nevertheless be stressed, as corruption essentially gets something for nothing (or no added value in terms of intellectual capital), whereas innovation uses intellectual capital to create added value, thus providing incentive to curb corruption and invest into innovative practices. As the triple helix model represents a higher level of decentralisation that puts business and academia (and also citizens in the quadruple helix model) at the same level of communication with the government, despite not having the monopoly on power that government has, it is able to effectively bypass corruption and create an oasis or an environment in which corruption loses its economic sense.. It means that those sectors of the society are not isolated in their silos, or that it is possible to establish communication between members of those sectors on an equal footing, thus leading to mutual projects that are formalised and implemented through joint ventures and other mutual organisations. So far only one cluster in Croatia has been based on quadruple helix methodology (HKKKKI - Croatian cluster of competition of creative and cultural industries), and only one competition involving social innovation based on quadruple helix was conducted in 2015, which was organised by OECD and attracted 30 projects, 10 of which were selected for final presentation and 3 of which were awarded as best social innovation projects.

\section{Conclusion}

In this paper we have given examples of successful innovation strategies based on triple helix model, such as MIT and agricultural settlements in Ottoman empire before the foundation of the state of Israel, but also problems that appeared in the Czech Republic. For instance, in comparison of Croatia with Czech Republic we found similarities, such as trying to escape the middle income trap, but also differences concerning culture and level of decentralisation. In those instances where a higher level of decentralisation or useful spillovers were achieved in Croatia, such as in Osijek county, results in innovation policy and investments were similar to those in the Czech Republic, or perhaps even better, which indicates that those are perhaps the most important barriers to triple helix innovation policy development in Croatia. It Is 
suggested, on the basis of social dynamics research, comparison with other countries and available data on innovation, corruption and participation, that success stories depend on a particular dynamic which gives a dominant position to academia, while the role of the government is auxiliary, secondary, and supportive. Thus the lines of hierarchy weakening the innovation process become themselves weakened, enabling more innovation and value creation. The fact that there is a (negative) correlation between comuption and innovation indicates that there is a particular kind of social dynamics related to hierarchies that strengthens corruption and weakens innovation, and that it is related to political power and government, or politicisation of society in general. Despite some limitations of this analysis and the possibility of other exogenous variables affecting this outcome, it is so general that this conclusion cannot be ruled out. Further research should focus on the importance of (insufficient) networking, communication between different sectors (business, academia, government), and lack of participative culture, as those also represent significant country specific barriers in Croatia. Models of social dynamics should be further elaborated, and sometimes even models suitable for studying simple animals may be useful for understanding human societies. Ordinarily, the absence of higherlevel cognitive ability, behavioural complexity, language skills, and elaborate cultural forms argue against applying lessons learned from studying social organization in simple creatures to the investigation of social systems in humans. However, finding that social interaction is so important in producing organized structures in fish strengthens the argument for investigating the importance of social dynamics in producing dominance hierarchies and other social structures in humans. Cultural and traditional factors influencing innovation should also be further studied and, where possible, measured and accounted for. Therefore, we propose further research on the basis of the proposed model(s) that could lead into further and better insights of social dynamics related to innovation.

\section{References}

1. Blazek, J., Uhlír, D. (2007), "Regional Innovation Policies in the Czech Republic and the Case of Prague: An Emerging Role of a Regional Level?", available at: https://www.researchgate.net/publication/233613531_Regional_Innovation_Policies_i n_the_Czech_Republic_and_the_Case_of_Prague_An_Emerging_Role_of_a_Regional Level $(28 / 05 / 2016)$

2. Chase, I.D., Tovey, C, Spangler-Martin, D, M Manfredonia, M. (2001), "Individual differences versus social dynamics in the formation of animal dominance hierarchies", available https://www.researchgate.net/publication/11407463_Individual_differences_versus_so cial_dynamics_in_the_formation_of_animal_dominance_hierarchies (05/05/2016)

3. Dubina, I. N., (2015), "Game Theory and Business Simulation Game Approaches to Innovation Ecosystem analysis", available http://www.universitypublications.net/ijas/0804/pdf/B5R373.pdf (23/05/2016)

4. Ełzkowitz, H. (2002), "MIT and the Rise of Entrepreneurial Science", London, Routledge

5. Ełzkowitz, H. (2002), "The Triple Helix of University Industry-Government: Implications for Policy and Evaluation", Working paper, Stockholm: Institutet för studier av utbildning och forskning.

6. Etzkowitz, H. (2008) "The Triple Helix", First Edition, New York: Routledge, pp. 164, ISBN 0415964512, available at: http://dx.doi.org/10.4324/9780203929605 (05/05/2016)

7. Hobson, E.A., Simon, DeD., "Social Feedback and Emergence of Rank in Animal Society", available

at: http://journals.plos.org/ploscompbiol/article/asset?id=10.1371/journal.pcbi.1004411.P DF $(08 / 05 / 2016)$ 
8. Kascheeva, M, Nabeshima, K. (2015), "Innovation Policy in Czech Republic", IDE Discussion Paper 506, available at: http://www.ide.go.jp/English/Publish/Download/Dp/506.html (16/05/2016)

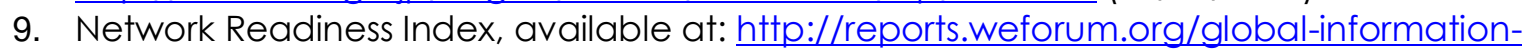
technology-report-2015/network-readiness-index/(30/05/2016)

10. Simmel, G. (1950), "Conflict and the Web of Group Affiliations", Glence: Free Press

11. Singer, S., Oberman Peterka, S., "Ocjena koncepta triple helix: kako testirati novi koncept sa starim pokazateljima" ("Triple Helix Evaluation: How To Test A New Concept With Old Indicators?"), available at: http://hrcak.srce.hr/93446 (25/05/2016)

12. Supporting Investment in Knowledge Capital, Growth and Innovation, OECD, Paris, 2013.

13. Tetrevova, L., "Triple Helix Model in Practice in the Czech Republic", available at: http://www.bm.vgtu.lt/index.php/bm/bm_2012/paper/view/213 (20/05/2016)

14. Tetrevova, L., Kostalova, J. (2015), "Triple Helix Model and Partnerships of Technical Faculties and Universities", available at: http://www.wseas.us/elibrary/conferences/2013/Chania/AEBDa/AEBDa-13.pdf (19/05/2016)

15. Tetrevova, L., Kostalova, J. (2015), "Problems of Application of Triple Helix in the Czech Republic", available at: http://www.wseas.us/elibrary/conferences/2012/Porto/AEBD/AEBD-05.pdf (22/05/2016)

16. Triple Helix Model (of Knowledge Based Economy) in Open Architecture Business Games, available at: http://www.leydesdorff.net/th8/TRIPLE\%2OHELIX\%20-\%20VII (25/05/2016)

17. Weizmann, Ch.(1949), "Conflict and the Web of Group Affiliations", Glencoe, Free Press.

\section{About the author}

Jan Klasinc is a Ph. D. candidate at the University of Zagreb and member of Croatian Institute of Public Administration. His scientific research is in the area of the interactions of public administration and business sector, public administration, governance, public economics, public finance, microeconomics, e-government, education and health policy, economics of innovation, economics of ICT, knowledge-based economy, smart cities, and applications of fuzzy logic, social networks, public participation and e-participation, social dynamics. Previously he graduated at the same University as a university specialist in economics with honours, with a thesis about FDI in Croatian ICT sector, university specialist in public administration with a thesis on effects of e-government in Croatia, and University Pantheon-Assas Paris II, with the thesis about legal harmonisation of Croatian law with the EU Acquis. He has participated in a number of international conferences. The author can be contacted at ajklasinc@gmail.com. 